\title{
Article \\ Effect of Freeze-Thaw Cycles on Carbonation Behavior of Three Generations of Repeatedly Recycled Aggregate Concrete
}

\author{
Hui Liu ${ }^{1,2}{ }^{\circ}$, Minqi Hua ${ }^{1}\left(\right.$, Pinghua Zhu ${ }^{1, *}$, Chunhong Chen ${ }^{1}$, Xinjie Wang ${ }^{1}$, Zhongqiu Qian ${ }^{3}$ and \\ Yanlong Dong 4 \\ 1 Department of Civil Engineering, Changzhou University, Changzhou 213164, China; \\ liuhui@cczu.edu.cn (H.L.); alcestle@gmail.com (M.H.); chench@cczu.edu.cn (C.C.); \\ wangxinjie@cczu.edu.cn (X.W.) \\ 2 State Key Laboratory of Silicate Materials for Architectures, Wuhan University of Technology, \\ Wuhan 430070, China \\ 3 Changzhou Architectural Research Institute Group Co., Ltd., Changzhou 213001, China; \\ qianzhongqiu@126.com \\ 4 Changzhou CRCC Urban Construction Component Co., Ltd., Changzhou 213000, China; \\ dongyanlong1@163.com \\ * Correspondence: zph@cczu.edu.cn
}

Citation: Liu, H.; Hua, M.; Zhu, P.; Chen, C.; Wang, X.; Qian, Z.; Dong, Y. Effect of Freeze-Thaw Cycles on Carbonation Behavior of Three Generations of Repeatedly Recycled Aggregate Concrete. Appl. Sci. 2021, 11, 2643. https://doi.org/10.3390/ app11062643

Academic Editor: Carlos Thomas

Received: 8 February 2021

Accepted: 12 March 2021

Published: 16 March 2021

Publisher's Note: MDPI stays neutral with regard to jurisdictional claims in published maps and institutional affiliations.

Copyright: (c) 2021 by the authors. Licensee MDPI, Basel, Switzerland. This article is an open access article distributed under the terms and conditions of the Creative Commons Attribution (CC BY) license (https:/ creativecommons.org/licenses/by/ $4.0 /$ )

\begin{abstract}
Multiple recycling of waste concrete has attracted widespread attention. This study presented the carbonation behavior of repeatedly recycled aggregate concrete (RRAC) used in a micro-frozen region. The effects of freeze-thaw cycles on the carbonation depth of three generations of RRAC with $25 \%, 75 \%$, and $100 \%$ of replacement rate were evaluated. All RRAC specimens after different numbers of freeze-thaw cycles were rapidly carbonated for $28 \mathrm{~d}$ indoors to test the carbonation resistance of concrete. The results suggested that the carbonation depth of RRAC subjected to freeze-thaw cycles is higher than that in the non-freeze-thaw condition. This is because the freeze-thaw damages cause the internal structure of RRAC to become porous and and prone to cracking, thus providing convenient channels for $\mathrm{CO}_{2}$ to react with the alkali in the cementitious materials. With the growth of replacement rate or recycling number, RRAC reveals serious freezethaw damage and inferior carbonation resistance, which is due to the continuous deterioration repeatedly recycled concrete aggregate (RRCA) quality. However, when the replacement rate was $25 \%$, the carbonation depth for the third generation of RAC was comparable to the second generation of RAC at a $75 \%$ replacement rate, and even the first generation of $100 \%$ RAC. To ensure better carbonation resistance durability of multiple recycling RAC, the low replacement rate of RRCA should be considered. For the third generation of RAC with the $100 \%$ replacement rate, its highest carbonation depth after freeze-thaw cycles was $9.16 \mathrm{~mm}$, which still met the design requirements for structural use in a micro-frozen region. This indicates that it is feasible for three generations of RRAC to be used in the micro-frozen environment and that RRAC has great engineering application potential and promotional value.
\end{abstract}

Keywords: repeatedly recycled aggregate concrete; carbonation behavior; freeze-thaw cycles; multiple generations of recycling; replacement rate

\section{Introduction}

Many countries are experiencing dramatic and swift urbanization in the worldwide, the result of which is followed by massive construction and demolition wastes (C\&DWs) and a huge demand of natural aggregate (NA). These C\&DWs cause serious environmental loads. The demand of NA results in overexploitation and shortage of NA resources, which greatly damages the ecological balance of aggregate-producing areas [1,2]. Utilizing these C\&DWs as recycled aggregates to prepare the recycled aggregate concrete (RAC) is an effective and proven method to solve the environmental and resource crises and realize a circular economy in conventional concrete industries [3-7]. Many countries around the world 
including USA, China, and EU are gradually extending RAC to practical projects [8-11]. At present, RAC has been widely used in building structures and pavements [12-14]. In this situation, the RAC utilization rate around the world is growing progressively with each passing year $[15,16]$. However, when such RAC reaches its service life, it will face the problem of being dismantled and becoming waste concrete again. To achieve the strategy of sustainable development, multiple recycling of RAC emerges, attracting widespread attention from scholars. Obtaining the utmost out of waste RAC and converting it to produce repeatedly recycled aggregate concrete (RRAC) will further improve the utilization rate of $C \& D W s$ and conserve natural resources effectively. Therefore, it is quite necessary to explore the multiple recycling potential of RAC.

Carbonation resistance is a key index affecting the durability of reinforced concrete structures $[17,18]$. Exploring the carbonation behavior of RRAC is an indispensable step which determines the application potential of RRAC. Concrete carbonation is a process in which $\mathrm{CO}_{2}$ in the atmosphere reacts with the alkali in the cement to make the pore water more acidic, thus lowering the $\mathrm{pH}$ and leading to the loss of passivation film for reinforcements $[19,20]$. In the previous work, the carbonation behavior of three generations of RRAC with $100 \%$ replacement rate were reported [21]. It was found that with the increasing of the recycling number, the repeatedly recycled concrete aggregate (RRCA) quality degraded seriously and the carbonation resistance of RRAC gradually declined. But this study only considered the effect of a single factor on the carbonation resistance of RRAC. In an actual engineering, the occurrence of concrete carbonation is always accompanied with other environmental factors [22,23]. In a micro-frozen region whose average monthly temperature of the coldest month is between $0 \sim-4{ }^{\circ} \mathrm{C}$, the concrete always inevitably suffers from freeze-thaw cycles. These regions make up about a third of China's territory. Therefore, it is necessary to investigate the effect of freeze-thaw cycles on the carbonation behavior of concrete used in micro-frozen regions.

Previous research has pointed out that the carbonation resistance of concrete in the cold region was worse than that only in the atmospheric environment [24-26]. This is attributed to the damages caused by freeze-thaw cycles in the cold environment. Guo et al. [27] and Yildirim et al. [28] reported that the mechanical properties and relative dynamic elastic modulus of RAC decreased and the mass loss increased with the rise of freeze-thaw cycles. Deng et al. [29] concluded that the porosity of recycled concrete increased with the increasing number of freeze-thaw cycles and proportion of recycled coarse aggregate. The freeze-thaw cycle is believed to bring about some micro- or macrocracks in the concrete, which can immediately provide pathways for further migration of $\mathrm{CO}_{2}$ [24]. Xiao [30] studied the carbonation behavior of natural aggregate concrete (NAC) in freeze-thaw circumstances. When NAC was firstly subjected to freeze-thaw cycles and then carbonized for a few days, the carbonation depth of NAC was obviously larger than that of NAC in a carbonized environment. Similar results have been found in the references of [23,24]. Mao et al. [31] reported the durability of recycled fine aggregate concrete under the actions of freeze-thaw and carbonation. The results indicated that crack propagation in concrete caused by the freeze-thaw damage resulted in the carbonation intensification of concrete, while the carbonation refining the pore structure could delay the freeze-thaw damage in the initial cycle. It is well known that compared with NA, recycled concrete aggregate (RCA) owns worse physical and mechanical properties due to the old attached mortar on its surface [32]. It has been proven that the carbonation resistance of RAC is inferior to that of NAC after freeze-thaw cycles due to the inferior properties of RCA [33]. If RAC is further repeatedly recycled into RRAC, with the growth of recycling number, it can be predicted that the carbonation resistance of RRAC would be degraded seriously. But their utilization rate and possible service life used in the micro-frozen region is not clear. Hence, it is of great academic and applied value to fill in the research gap regarding whether RRAC could be used in the micro-frozen region and to verify the utilization potential of RRAC. 
In this study, three generations of RRAC were prepared by different replacement rates $(25 \%, 75 \%$, and $100 \%)$ of RRCA. The carbonation depth of three generations of RRAC under different freeze-thaw cycles (100-800 times) was measured to explore the effect of freeze-thaw damage on the carbonation resistance of RRAC. A research hypothesis that three generations of RRAC can be applied in actual projects in a micro-frozen region was verified by evaluating the carbonation resistance of RRAC during the whole service life.

\section{Experimental}

\subsection{Materials}

The experimental materials used in this study were consistent with ones in previous work [21]. P.O 52.5 Portland cement manufactured by Jiangsu Yangzi Cement Co. Ltd. (Changzhou, China) was used to prepare the three generations of RRAC. Granulated blastfurnace slag (GBFS), fly ash (FA), and silica fume (SF) were added as mineral admixtures. Considering strength, durability, and workability, etc. of concrete, the content of FA, GBFS, and SF was $20 \%, 10 \%$, and $5 \%$ by weight of all cementitious materials, respectively. River sand whose apparent density was $2586 \mathrm{~kg} / \mathrm{m}^{3}$ and fineness modulus was 2.4 was adopted as a fine aggregate. Natural coarse aggregate (NCA) with a particle size of $4.75-26.5 \mathrm{~mm}$ was applied to cast NAC as the control group. In addition, air entraining admixture (AEA) and polypropylene fiber (PP) were used as additives in the preparation process of RRAC. Polycarboxylic acid (PCA) as superplasticizer was used in all concrete groups. The dosage of polycarboxylic was $1.8 \mathrm{wt} . \%$ of cementitious material to ensure that the workability of all concrete could meet the slump value requirement of $150 \mathrm{~mm}$.

\subsection{Preparation of $R R C A$ and $R R A C$}

Figure 1a reveals the preparation process of three generations of RRCA and RRAC. A design service life of 50 years for RAC was defined as a generation in this study. The first-generation recycled aggregate $(4.75-26.5 \mathrm{~mm})$ marked as RCA-1 was provided from Jiangsu Lvhe Environmental Technology Co. Ltd. (Changzhou, China) to prepare the first generation RAC (RAC-1). To achieve the equivalence of a 50-year service life of concrete and prepare the second (RCA-2)- and third (RCA-3)-generation recycled aggregates by a laboratory acceleration process, the multi-environmental time similarity theory [34] was adopted. The cured RAC- 1 was carbonated for $17 \mathrm{~d}$ indoor under $30 \%$ of its ultimate tensile stress, which was equal to concrete carbonated for 50 years in the natural environment. The loading procedure of RAC- 1 followed the previous study [35], and the loading device is shown in Figure 1b. Then the RAC-1 was crushed by a two-grade crushing technique and sieved to obtain the RCA-2 (4.75 26.5 mm). Similarly, RCA-3 and the second (RAC-2)- and third (RAC-3)-generation RAC were prepared. The physical properties, phase compositions, and morphologies of three generations of RRCA had been described in the previous research [21]. All RRAC could meet the requirements for medium quality aggregates. The grading curves of NCA and RRCA are shown in Figure 2. All the cumulative sieve residual rates of NCA and RRCA conformed to the continuous grading requirements of a 5-20-mm aggregate diameter in accordance with GB/T 25177-2010. Three generations of RRAC with $40 \mathrm{MPa}$ of target strength were prepared using the corresponding RRCA at different replacement rates $(25 \%, 75 \%$, and $100 \%)$, which were labeled as RRAC-25, RRAC-75, and RRAC-100. 
(a)

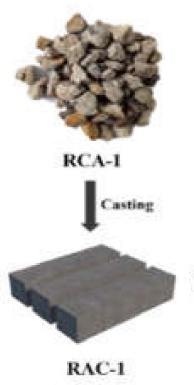

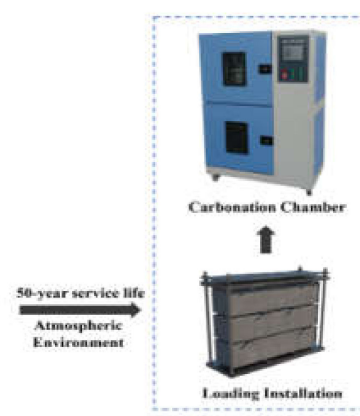
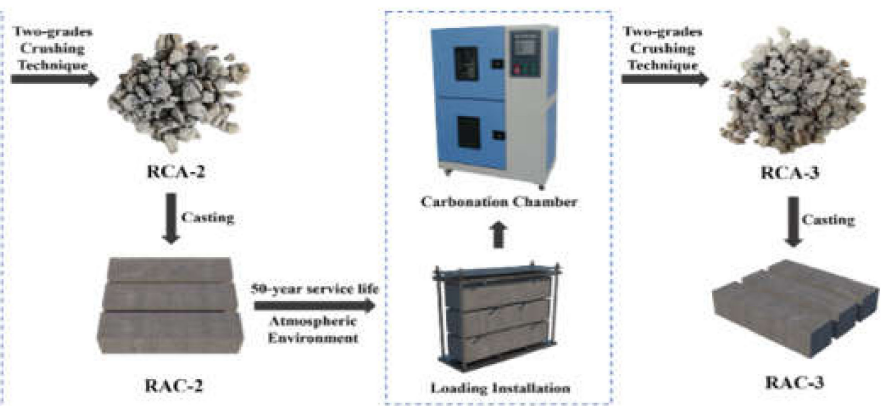

(b)

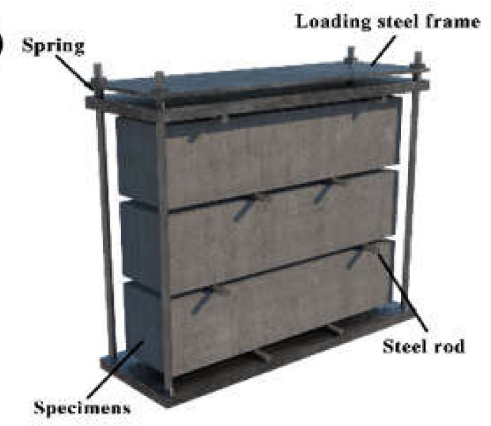

Figure 1. (a) Schematic for preparation process of recycled concrete aggregate (RCA) and repeatedly recycled aggregate concrete (RRAC) and (b) loading device of RRAC.

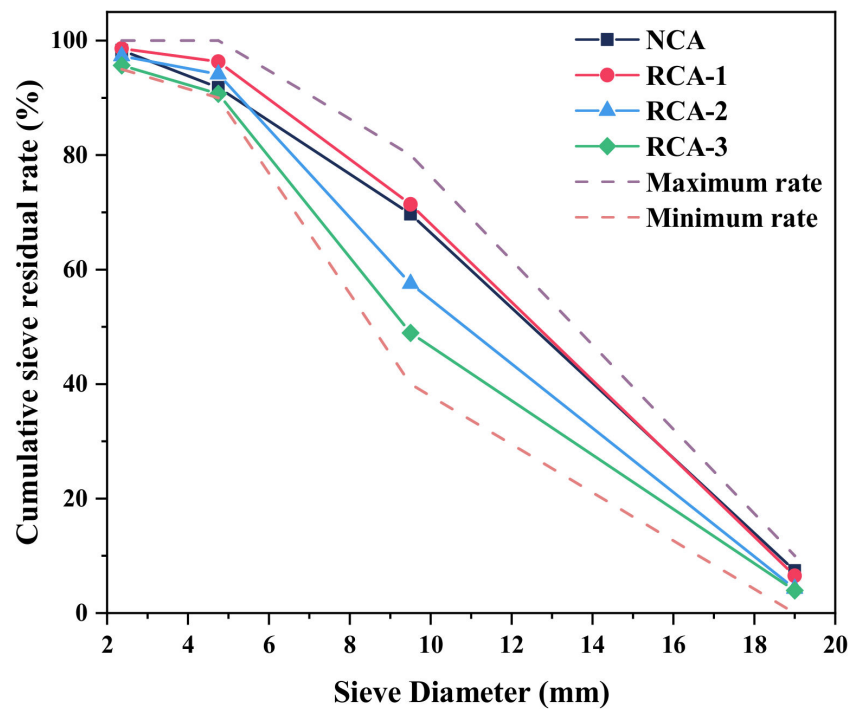

Figure 2. Grading curve of natural aggregate concrete (NCA) and RRCA.

The mixed proportions of NAC and RRAC are given in Table 1. Cube specimens $(100 \times 100 \times 100 \mathrm{~mm})$ of RRAC were prepared for measuring compressive strength. Twentyseven $100 \times 100 \times 400 \mathrm{~mm}$ prism samples for each group of RRAC and NAC were cast for the freeze-thaw cycle and accelerated carbonation test. All specimens were demolded after $24 \mathrm{~h}$ and preserved in a standard curing room $\left(20 \pm 3{ }^{\circ} \mathrm{C}, \mathrm{RH}>90 \%\right)$ until the age of $28 \mathrm{~d}$. The specimens for freeze-thaw cycles needed to be taken out 4 days in advance and soaked in $\left(20 \pm 2{ }^{\circ} \mathrm{C}\right)$ water until the freeze-thaw cycle began. The freeze-thaw cycles (100-800 times) of RRAC were carried out by the quick-freezing method in the laboratory. After subjecting to the freeze-thaw cycles, the NAC and RRAC specimens were carbonated in a standard carbonation box $\left(20 \pm 3 \%\right.$ of $\mathrm{CO}_{2}$ concentration, $70 \pm 5 \%$ of $\mathrm{RH}$ and $20 \pm 2{ }^{\circ} \mathrm{C}$ of temperature) for $28 \mathrm{~d}$. 
Table 1. Mixed proportions of NAC and RRAC.

\begin{tabular}{|c|c|c|c|c|c|c|c|c|c|c|c|}
\hline Concrete Types & Cement & NCA & RCA & Sand & GBFS & FA & SF & AEA & PCA & $\mathbf{P P}$ & Water \\
\hline NAC & 270 & 946 & 776 & - & 41 & 83 & 21 & 0.21 & 7.42 & 0.41 & 185.7 \\
\hline RAC-1-25 & 270 & 709.5 & 795 & 217.8 & 41 & 83 & 21 & 0.21 & 7.42 & 0.41 & 195.4 \\
\hline RAC-2-25 & 270 & 709.5 & 881 & 189.3 & 41 & 83 & 21 & 0.21 & 7.42 & 0.41 & 195.5 \\
\hline RAC-3-25 & 270 & 709.5 & 904 & 170.5 & 41 & 83 & 21 & 0.21 & 7.42 & 0.41 & 191.3 \\
\hline RAC-1-75 & 270 & 236.5 & 795 & 653.3 & 41 & 83 & 21 & 0.21 & 7.42 & 0.41 & 215 \\
\hline RAC-2-75 & 270 & 236.5 & 881 & 567.8 & 41 & 83 & 21 & 0.21 & 7.42 & 0.41 & 215.2 \\
\hline RAC-3-75 & 270 & 236.5 & 904 & 511.5 & 41 & 83 & 21 & 0.21 & 7.42 & 0.41 & 202.6 \\
\hline RAC-1-100 & 270 & - & 795 & 871 & 41 & 83 & 21 & 0.21 & 7.42 & 0.41 & 224.8 \\
\hline RAC-2-100 & 270 & - & 881 & 757 & 41 & 83 & 21 & 0.21 & 7.42 & 0.41 & 225 \\
\hline RAC-3-100 & 270 & - & 904 & 682 & 41 & 83 & 21 & 0.21 & 7.42 & 0.41 & 208.2 \\
\hline
\end{tabular}

GBFS: Granulated blast-furnace slag; FA: Fly ash; SF: Silica fume; AEA: Air entraining admixture; PCA: Polycarboxylic acid; PP: Polypropylene fiber.

\subsection{Measurements}

The workability of fresh concrete was tested in accordance with standard ASTM C143 [36]. The compressive strength of NAC and RRAC was tested by standard ASTM C109 [37]. In each group, three specimens were tested to obtain the average compressive strength.

The carbonation resistance of NAC and RRAC before and after subjecting freezethaw cycles were assessed using rapid carbonation method according to standard GB/T 50082-2009 [38].

SEM images were taken by Zeiss SUPRA55 to observe the micro-morphology of RRAC under the action of freeze-thaw cycles and carbonation.

\section{Results}

\subsection{Workability and Compressive Strength of RRAC}

\subsubsection{Workability}

The workability of all concrete was set as $150 \pm 15 \mathrm{~mm}$ and the measured values are shown in Figure 3. To ensure the well workability of fresh concrete, the dosages of additional water were adjusted according to the water absorption of RRCA.

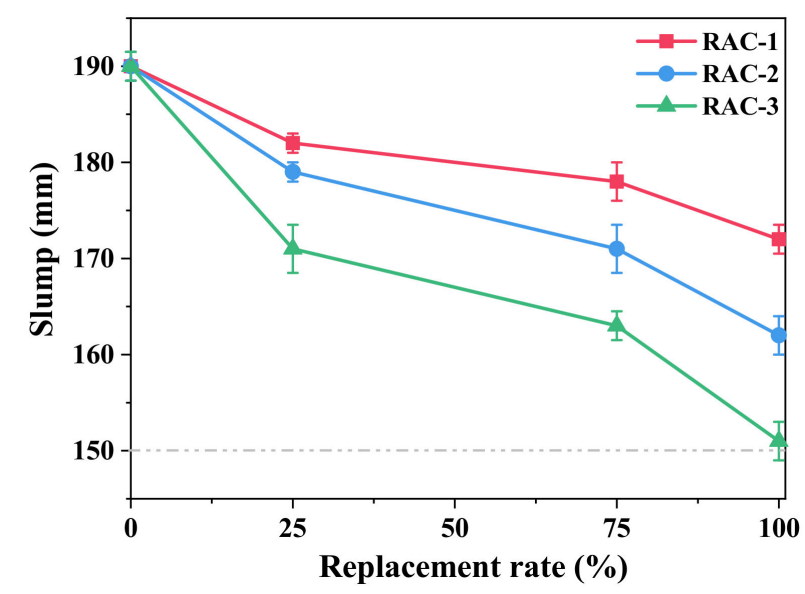

Figure 3. Workability of RRAC with different replacement rates.

As shown in Figure 3, all the slump values of RRAC were more than $150 \mathrm{~mm}$, which satisfied the design index. But the slump values of RRAC were lower than that of NAC, and showed a downward trend when the replacement rate or recycling number of RRCA increased. Compared with NAC, the slump values of RAC-1-25, RAC-2-25, and RAC-3-25 reduced by $4.2 \%, 5.8 \%$, and $10.0 \%$, respectively. For RAC-3, the slump values declined by 
$10.0 \%, 14.2 \%$, and $20.5 \%$ with the increase of replacement rate. Both the high replacement rate and recycling number led to more loss in the workability of concrete, which was attributed to the increase of attached mortar contents and the number of fissures in RRCA. The high content of the attached mortar and loose and porous structure of RRCA resulted in an increase in water demand of RRAC, thus reducing the workability. In addition, RCA was more irregular in shape and rougher on the surface [39], which also reduced its mobility in concrete to reduce the workability.

\subsubsection{Compressive Strength}

The compressive strength of all concrete groups and the strength loss rate of RRAC relative to NAC are shown in Figure 4. The loss rate of compressive strength for RRAC increased, and its compressive strength gradually decreased with the growth of RRCA replacement rate and recycling number. The loss rates of RAC-1 were only $1.43 \%, 2.86 \%$, and $3.68 \%$, indicating that RAC-1 owned well strength close to that of NAC, especially at a low replacement rate (25\%). But the strength loss rate of RAC-2 and RAC-3 increased significantly with the increase of the RRCA replacement rate. At a 100\% replacement rate, RAC-3 had the largest loss rate, reaching $17.38 \%$. Even though the compressive strength of RRAC decreased severely at a high replacement rate and great recycling number, all three generations of RRAC reached the target strength of $40 \mathrm{MPa}$. Therefore, it was feasible to prepare RRAC by using multiple recycling RCA for structural use in terms of compressive strength.
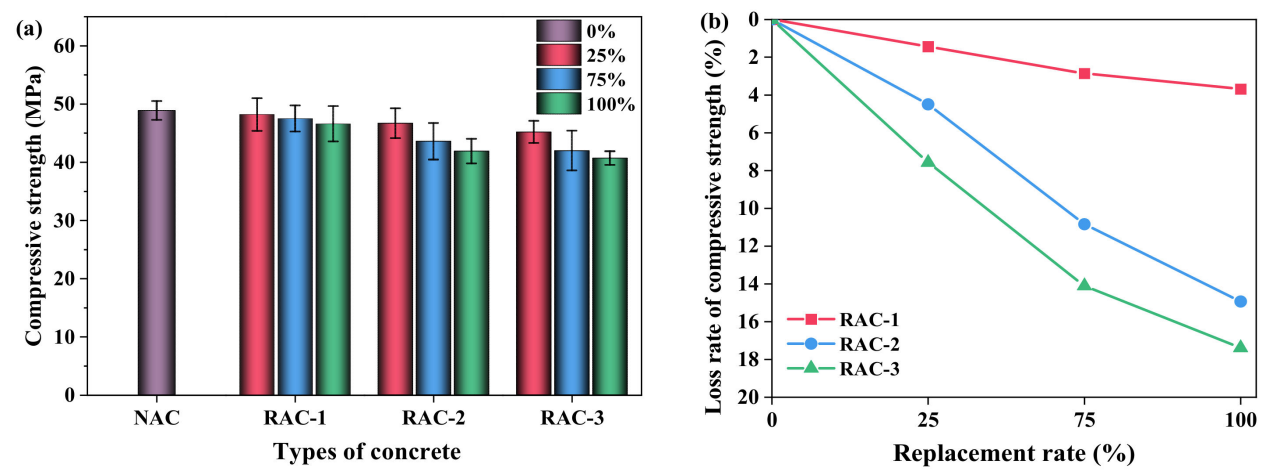

Figure 4. Compressive strength (a) and its loss rate (b) of RRAC at $28 \mathrm{~d}$.

The falloff of the mechanical property of RRAC was attributed to the degraded quality of RRCA, such as high porosity, low density, high water absorption, etc., as well as the complex interfacial transition zone (ITZ) in RRAC (Figure 5). NAC owned only new ITZ between NCA and new mortar. However, as shown in Figure 5a, for the first generation RAC, three types of ITZs were introduced: (1) The old ITZ (O-ITZ) between the old attached mortar and original aggregate in RCA (black line); (2) the new ITZ (N-ITZ) between the original aggregate and new mortar (blue line); and (3) the mortar ITZ (M-ITZ) between the old attached mortar and new mortar (orange line). O-ITZ and M-ITZ produced by the attached mortar were the weakest part in recycled concrete [40]. Thus, new cracks in RAC were more likely to appear under the action of external force. When the waste concrete was multiple recycled, the ITZ became more complex, as displayed in Figure 5b, because another old mortar ITZ (marked as OM-ITZ) between the old attached mortar and next generation attached mortar appeared (green line). In addition, a great number of micro-cracks occurred in the attached mortar even inside the aggregate due to the iterative crushing processes in the preparation of RRCA [41]. These factors aggravated the decline in the quality of RRCA and compressive strength of RRAC. 

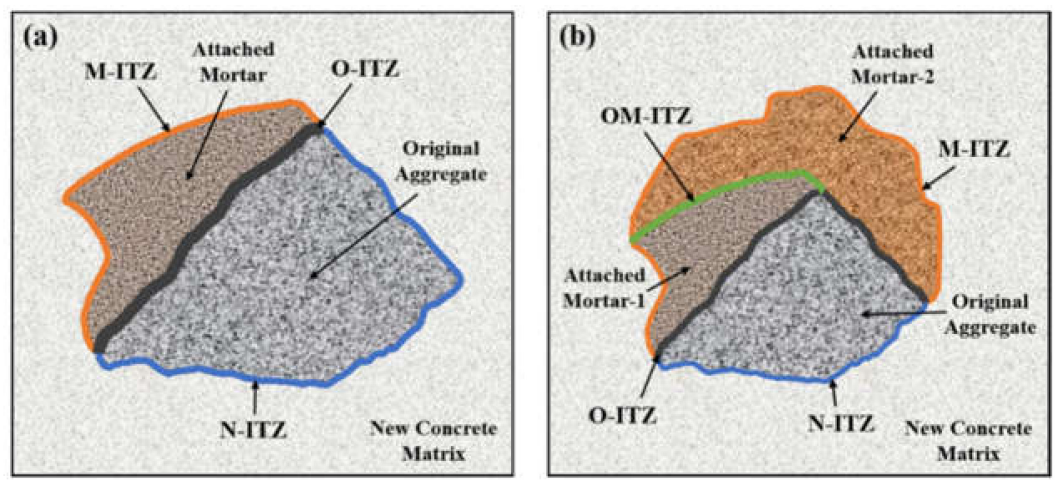

Figure 5. Schematic diagram of interfacial transition zones (ITZs) in (a) RAC-1 and (b) RAC-2.

\subsection{Carbonation Behavior of RRAC after Freeze-Thaw Cycles}

Carbonation is an inevitable reaction during the use of cement concrete in a natural atmospheric environment. Carbonation depth indicates the carbonation resistance durability of concrete. Figures 6-8 exhibit the carbonation depth of RRAC with different replacement rates before and after freeze-thaw cycles.
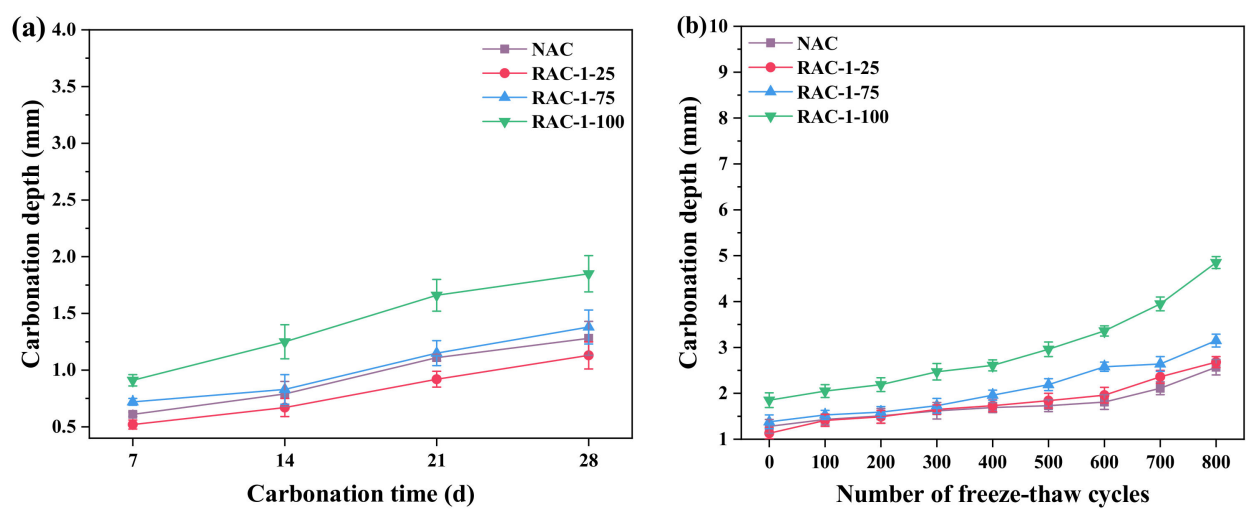

Figure 6. Carbonation depth of RAC-1 with different replacement rates (a) before and (b) after freeze-thaw cycles.
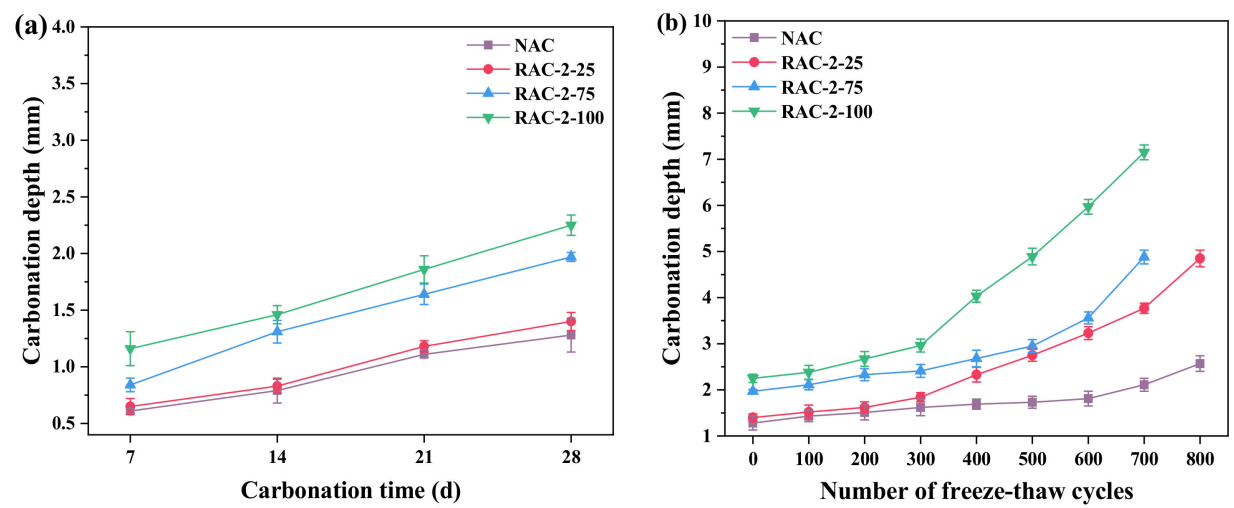

Figure 7. Carbonation depth of RAC-2 with different replacement rates (a) before and (b) after freeze-thaw cycles. 

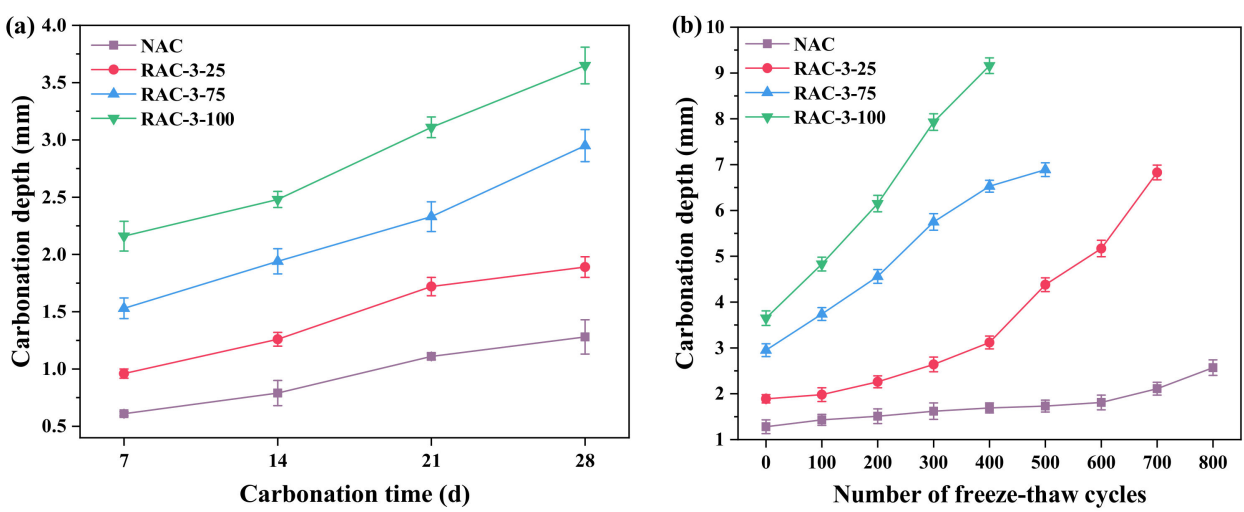

Figure 8. Carbonation depth of RAC-3 with different replacement rates (a) before and (b) after freeze-thaw cycles.

\subsubsection{The First Generation}

The time-evolution of carbonation depths for RAC- 1 at different replacement rates is displayed in Figure 6a. It is no doubt that the carbonation depths of concrete increased as time went on, and the carbonation resistance of RAC- 1 became poor when the replacement rate increased. On the whole, the carbonation depth of RAC-1-25 and RAC-1-75 was similar to that of NAC, indicating that the carbonation resistance of RAC- 1 with non$100 \%$ of replacement rate was comparable to that of NAC. Especially at low replacement rates $(25 \%)$, the carbonation depths of RCA-1 were even lower than the NAC ones. This was due to the attached mortar on the surface of RCA, which reacted with $\mathrm{CO}_{2}$ to form the carbonation products. These products filled in the micro-pores and micro-cracks in the attached mortar to enhance the weak ITZs [42], thus blocking the $\mathrm{CO}_{2}$ penetration in concrete to some extent. But with the increase of attached mortar content namely replacement rate, the poor performance of attached mortar and ITZs in RAC began playing the leading role. The increasing pores and cracks in the attached mortar and the loose ITZs made it easier for $\mathrm{CO}_{2}$ to penetrate into RAC [43]. Therefore, when the total attached mortar content in RAC exceeded a certain degree, the carbonation depth of RAC was be greater than that of NAC [44].

The concrete structures used in micro-frozen regions are inevitably subjected to more or less freeze-thaw cycles. Predictably, freeze-thaw damage for concrete accelerates its carbonization. Figure $6 \mathrm{~b}$ shows the $28-\mathrm{d}$ carbonation depth variations of NAC and RAC-1 after different freeze-thaw cycles. The carbonation depth of all concretes increased gently as the freeze-thaw cycle went on. For NAC, the carbonation depth grew slowly before 600 freeze-thaw cycles, and the depth value increased by $41.4 \%$ compared to that of specimens under non-freeze-thaw conditions. But when freeze-thaw cycles increased unceasingly to 800 times, the carbonation depth reached 2 times as much as that of unfreeze-thaw specimens. Such a variation trend was also applicable to RAC-1-25. The carbonation depth of RAC-1-25 was close to the NAC one, showing that RAC- 1 with low replacement rate owned comparable carbonation resistance durability of NAC. At a 75\% replacement rate, the carbonation depth of RAC- 1 increased rapidly after 300 freeze-thaw cycles. When the replacement rate was $100 \%$, the carbonation depth of RAC- 1 showed an exponential growth trend. This indicated that freeze-thaw damage and high contents of RCA-1 weakened the carbonation resistance of RAC- 1 . But for the first generation RAC, its carbonation resistance was acceptable especially at $25 \%$ and $75 \%$ replacement rates. In addition to the attached mortar of RCA retarding the $\mathrm{CO}_{2}$ penetration in RAC, the relatively few micro-cracks and micro-pores in RCA accommodated more free water, which greatly alleviated the seepage pressure and expansion stress caused by icing in the early stage of freeze-thaw process. Minor freeze-thaw damage appeared in the RAC-1, resulting in a lower carbonation depth. But with the raise of replacement rate, the contents of attached mortar, micro-cracks, and micro-pores increased, which provided more channels for water and $\mathrm{CO}_{2}$ media, leading to major freeze-thaw damage and poor carbonation resistance. 


\subsubsection{The Second Generation}

Figure 7 shows the carbonation depths of second-generation RAC before and after freeze-thaw cycles. As shown in Figure 7a, the carbonation depth of RAC-2-25 was close to that of NAC. Similar to RAC-1, the attached mortar in RCA-2 slightly retarded the carbonation reaction of RAC-2. But when the replacement rate continued to rise, the carbonation depths of RAC-2 increased linearly. At the replacement rate of $100 \%$, the carbonation depth of RAC-2 rose by $75.8 \%$ compared with the NAC one at a $28-\mathrm{d}$ carbonation age. With the rise of the carbonation age, the overall growth trend was relatively gentle. The carbonation depth and carbonation time were approximately proportional to each other.

RAC-2 after freeze-thaw cycles was more likely to be carbonated, as displayed in Figure $7 \mathrm{~b}$. The carbonation depth of RAC-2 after freeze-thaw cycles increased faster than those of NAC and RAC-1, especially when the freeze-thaw cycle exceeded 300 times. The carbonation depth of RAC-2-100 showed a linear growth trend after 300 times of freezethaw cycles and the carbonation depth reached $7.15 \mathrm{~mm}$ after 700 times of freeze-thaw, which increased by 2 times compared with that before the freeze-thaw cycle. Freeze-thaw cycles resulted in the deterioration of pores and cracks in the concrete structure and the spalling of its surface mortar, which allowed $\mathrm{CO}_{2}$ to penetrate into the concrete and increase the $\mathrm{CO}_{2}$ diffusion coefficient [24]. Therefore, the RRAC specimens after freeze-thaw cycles were more susceptible to be carbonated, compared to those exposed in the non-freeze-thaw condition.

\subsubsection{Third Generation}

For the third-generation RAC, its carbonation resistance deteriorated sharply. With the increase of replacement rate, the carbonation depths of RAC-3 increased significantly (Figure 8a). In other words, the influence of the replacement rate on the carbonation resistance of RAC-3 was particularly severe. When the replacement rate reached $100 \%$, the carbonation rate of RAC-3 showed a substantial increase compared with that at a low replacement rate. The carbonation depth of RAC-3 with $100 \%$ replacement rate at a $28-\mathrm{d}$ carbonation age was $3.65 \mathrm{~mm}$, which was 1.85 times higher than that of NAC. This was caused by the poor quality of RCA-3 and the cumulative effect of carbonation [21]. In the preparation process of every generation RCA, the matrix concrete was carbonated under the $30 \%$ of ultimate tensile stress for $17 \mathrm{~d}$ to simulate the real service life, thus leading to the partially attached mortar being carbonated. The greater the generation, the more obvious the accumulation effect of carbonation.

In Figure 8b, the carbonation resistance of RAC-3 falls off further with the increase of replacement rate and number of freeze-thaw cycles. After 400 times of freeze-thaw cycles, the carbonation depths of RAC-3-25, RAC-3-75, and RAC-3-100 were 3.12, 6.53, and $9.16 \mathrm{~mm}$, respectively. Compared with the NAC one, the carbonation depth increased by $84.6 \%, 286 \%$, and $442 \%$, respectively, and the maximum carbonation depth of RAC-3 was 2.5 times higher than that in the non-freeze-thaw condition. It was found that the effect of freeze-thaw cycles on the carbonation resistance of RAC-3 was more detrimental. In the micro-frozen regions, the freeze-thaw cycle could be a significant factor to the deterioration of pore structure of concrete [45]. Under different pore structures, the difference of $\mathrm{CO}_{2}$ diffusion coefficient resulted in the changes of carbonation resistance of RAC [46]. In addition, the poor properties of RCA-3 also played a prominent role in the deterioration of carbonation resistance of RAC-3 [47]. The new mortar on the RAC-3 surface fell off easily after freeze-thaw cycles due to the weaker ITZs caused by the RCA-3, and $\mathrm{CO}_{2}$ was much easier to penetrate in the concrete, increasing the $\mathrm{CO}_{2}$ diffusion coefficient. Therefore, freeze-thaw damage and the quality of RCA were the critical factors to affect the carbonation resistance of RAC.

\subsection{SEM Analysis}

It can be seen from the above that RAC-1 possessed the best carbonation resistance which was equivalent to that of NAC. Therefore, RAC-1 with different replacement rates 
subjected to freeze-thaw cycle for 600 times and carbonized for $28 \mathrm{~d}$ was chosen for SEM analysis, which are shown in Figure 9. After freeze-thaw and carbonation processes, the micro-morphology of RAC-1 had changed with different replacement rates. When the replacement rate was $25 \%$, the internal structure of RAC- 1 was relatively dense with almost no pores and micro-cracks, and a small amount of carbonation reaction products such as $\mathrm{CaCO}_{3}$ existed on the surface to fill in the pores. With the increase of replacement rate, the internal structure of specimen began to become loose and the cracks appeared. When the replacement rate was $100 \%$, cracks in concrete were formed and developed in large quantities to provide the reaction channels for carbonation. In addition, a large number of carbonation reaction products were attached on the surface of concrete, but these carbonation products were not enough to fill these cracks (Figure 9c). Therefore, the carbonation resistance of RAC-1-100 was worse than that of RAC-1-25 and RAC-1-75.
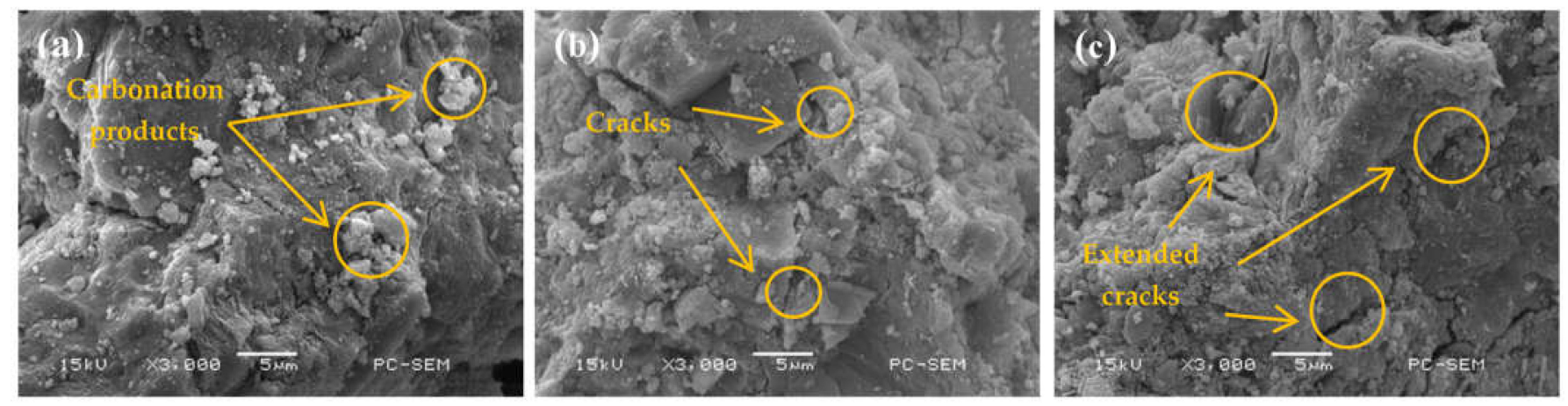

Figure 9. SEM images of RAC-1 with different replacement rates carbonated for $28 \mathrm{~d}$ after 600 times of freeze-thaw cycles: (a) $25 \%$; (b) $75 \%$; (c) $100 \%$.

This is mainly because that the freeze-thaw cycle is essentially a process in which the hydration products of concrete change from compact to loose. The freeze-thaw damages of RAC were aggravated with an increase of the replacement rate due to the inferior properties of RCA, which have been verified as previous work [6]. These damages intensified the development of internal pores and micro-cracks in concrete, thus providing more channels for $\mathrm{CO}_{2}$ to initiate a carbonation reaction, thus decreasing the carbonation resistance of RAC.

To explore the effect of the freeze-thaw cycles on the carbonation resistance of RAC, the morphologies of RAC-2-75 carbonated for $28 \mathrm{~d}$ after different freeze-thaw cycles were observed by SEM (Figure 10). After 200 times of freeze-thaw cycles, RAC-2 was still relatively dense. Its surface contained a small amount of $\mathrm{CaCO}_{3}, \mathrm{SiO}_{2}$, and other substances formed by carbonation. But micro-cracks and pores began to form inside of RAC-2, and RAC- 2 became loose and porous after 400 times of freeze-thaw cycles, which accelerated the carbonation of concrete. A growing number of carbonation products appeared on the concrete surface. When the freeze-thaw cycle reached 600 times, the pores generated in the early stage of concrete gradually expanded, forming large holes and cracks, causing the structure of RAC to significantly deteriorate. The ITZs in concrete gradually became fuzzy, and a large number of carbonation products attached to the surface of concrete.

With fewer freeze-thaw cycles, the presence of micro-pores and micro-cracks in RCA provided more space for free water; thus, RAC showed good freeze-thaw resistance. However, with the increasing number of freeze-thaw cycles, free water migrated and was frozen repeatedly inside the pores of RAC-2. The freeze-thaw damages caused by hydrostatic pressure on pore wall were gradually accumulated and the internal structure gradually became porous [48]. These porous structures caused by freeze-thaw damages provided quick channels for $\mathrm{CO}_{2}$ to accelerate the carbonation reaction of concrete. Therefore, the freezethaw of concrete was the key factor to determine the carbonation resistance durability of $\mathrm{RAC}$ at the same replacement rate in a micro-frozen region. 

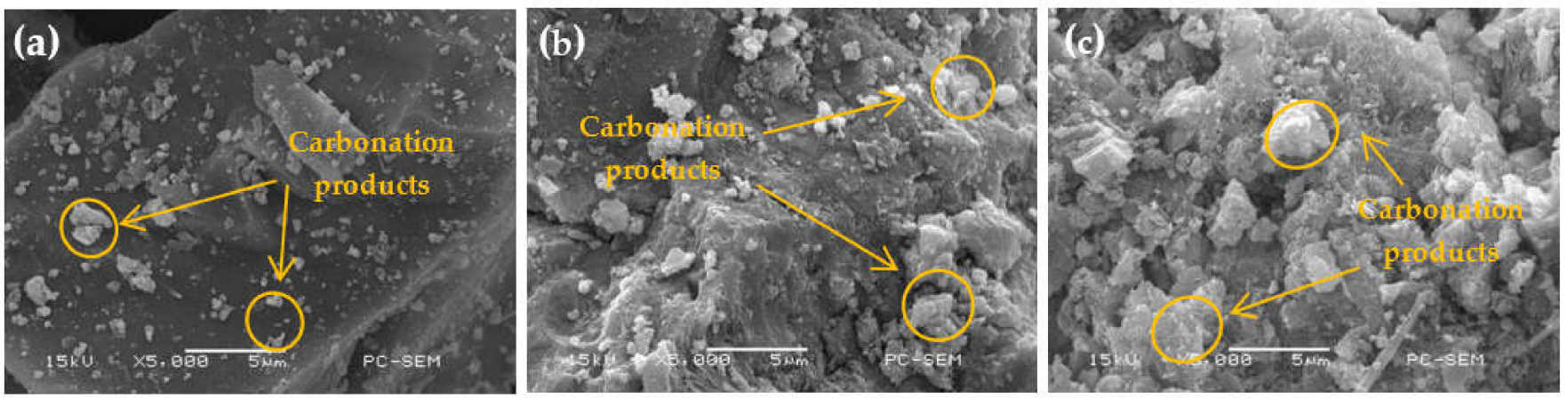

Figure 10. SEM images of RAC-2-75 carbonized for 28 days after different freeze-thaw cycles: (a) 200; (b) 400; (c) 600.

\section{Discussion}

It was found that the replacement rate and the recycling number of RRCA and freezethaw cycles of RRAC played critical roles in the carbonation resistance of RRAC used in the micro-frozen regions, as shown in Figure 11 and Table 2. The carbonation resistance of all three generations of RRAC gradually deteriorated with the growth of the replacement rate and recycling number of RRCA, and the freeze-thaw cycles.

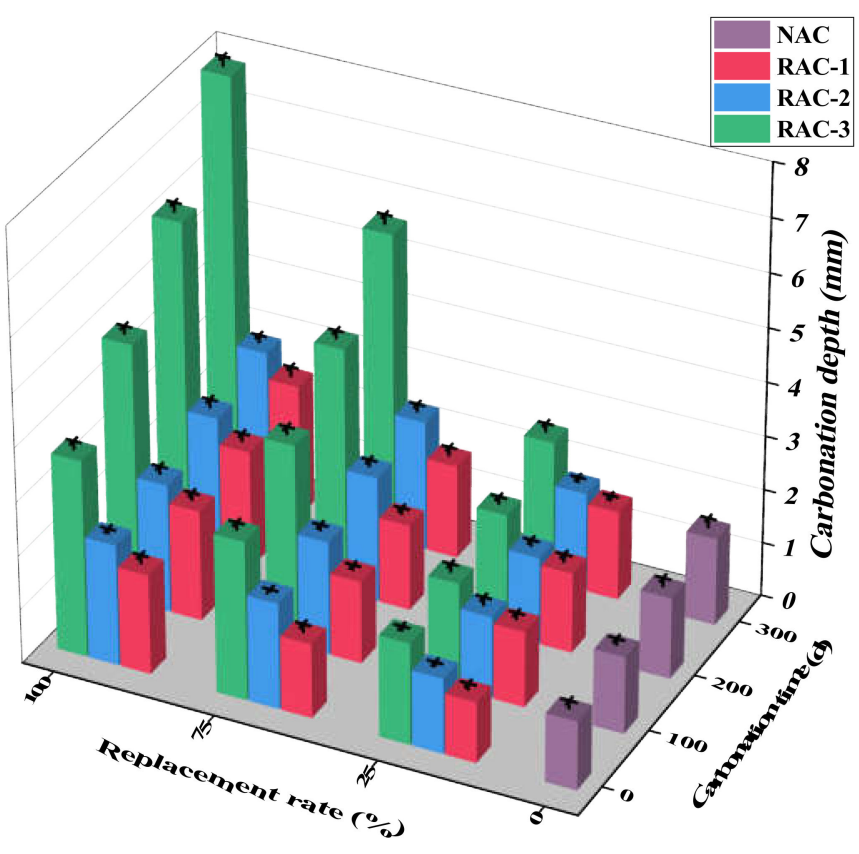

Figure 11. The 28-d carbonation depth of NAC and RRAC after 0-300 times of freeze-thaw cycles.

Table 2. Growth rate of carbonation depth for RRAC with different replacement rates relative to NAC after 0-300 times of freeze-thaw cycles.

\begin{tabular}{ccccc}
\hline Number of Freeze-Thaw Cycles & $\mathbf{0}$ & $\mathbf{1 0 0}$ & $\mathbf{2 0 0}$ & $\mathbf{3 0 0}$ \\
\hline RAC-1-25 & $-11.7 \%$ & $-1.4 \%$ & $-1.3 \%$ & $1.9 \%$ \\
RAC-1-75 & $7.8 \%$ & $7.0 \%$ & $5.3 \%$ & $6.8 \%$ \\
RAC-1-100 & $44.5 \%$ & $43.4 \%$ & $45.0 \%$ & $52.5 \%$ \\
RAC-2-25 & $9.4 \%$ & $6.3 \%$ & $7.3 \%$ & $13.6 \%$ \\
RAC-2-75 & $53.9 \%$ & $47.6 \%$ & $54.3 \%$ & $48.8 \%$ \\
RAC-2-100 & $75.8 \%$ & $66.4 \%$ & $76.8 \%$ & $82.7 \%$ \\
RAC-3-25 & $47.7 \%$ & $38.5 \%$ & $49.7 \%$ & $63.0 \%$ \\
RAC-3-75 & $130.5 \%$ & $161.5 \%$ & $202.0 \%$ & $254.9 \%$ \\
RAC-3-100 & $185.2 \%$ & $237.8 \%$ & $307.3 \%$ & $389.5 \%$ \\
\hline
\end{tabular}


At the same replacement rate, whether or not it went through the freeze-thaw cycles, the carbonation depths of RRAC increased with the growth of the recycling number of RCA. The carbonation depths of RAC-1-25, RAC-2-25, and RAC-3-25 under the non-freeze-thaw condition were 1.13,1.40, and $1.89 \mathrm{~mm}$, respectively. After 100 times of freeze-thaw cycles, the carbonation depths of RAC-1-100, RAC-2-100, and RAC-3-100 were 2.05, 2.38, and $4.83 \mathrm{~mm}$, respectively. This was attributed to the deterioration of RRCA quality, such as the decreasing apparent density, increasing attached mortar content and crushing index, and the increasing of recycling number [21]. Compared with NCA, the apparent density of RCA-1, RCA-2, and RCA-3 decreased by 5.9\%, 9.4\%, and $15.9 \%$, respectively, and the attached mortar content of RRCA increased from $40.3 \%$ to $55.4 \%$, as reported in a previous study [21]. The poor qualities of RRCA caused higher porosity and cracks in RRAC than the NAC one, which facilitated the diffusion of $\mathrm{CO}_{2}$ in RAC.

In a micro-frozen region, the freeze-thaw damage is another inevitable factor contributing to the degradation of carbonation resistance for RRAC. The more serious such damage, the worse the carbonation depth of RRAC. After 100, 200, and 300 times of freezethaw cycles, the carbonation depth of RAC-3-100 increased by $32.3 \%, 68.5 \%$, and $117.3 \%$ compared to that of concrete not subjected to freeze-thaw cycles. As reported by $\mathrm{Wu}$ et al. [49] and Deng et al. [29], the freeze-thaw damages of concrete are usually manifested as the growth of porosity and micro-cracks caused by the appearance of frost heaving and osmotic pressure. These damages result in cracking and spalling of cement mortar on the surface of concrete, thus providing more convenient channels for $\mathrm{CO}_{2}$ penetrating into concrete. It should be noted that, according to equivalent principle between laboratory freeze-thaw cycle and that in natural environment proposed by Jin et al. [50], the damage caused by 300 times of accelerated freeze-thaw cycles indoors is equal to the damage of concrete used in micro-frozen areas for 50 years. No RRACs, even RAC-3-100, suffered freeze-thaw failure after such freeze-thaw cycles, which has been verified by Zhu et al. [21].

Although the carbonation resistance of RRAC was degraded due to the freeze-thaw damage, RRCA replacement rates and recycling numbers, and the carbonation depth of all RRAC, even RAC-3-100, were still much lower than the protective thickness of reinforced concrete based on the standard for design of concrete structure durability of GB/T 504762019 [51]. This suggested that the three generations of RRAC can be used in micro-frozen regions for engineering applications for at least 50 years.

\section{Conclusions}

In this study, three generations of RRAC were prepared from the multiple recycling of C\&DW concrete with different RRCA replacement rates $(25 \%, 75 \%$, and $100 \%)$. The properties of fresh and harden concrete, carbonation behavior, and micro-morphologies of three generations of RRAC before and after freeze-thaw cycles were investigated. The conclusions can be drawn from this research as follows:

- The workability and compressive strength of RRAC decreased with the increase of RRCA replacement rate and recycling number. The workability and compressive strength of RRAC were inferior to that of NAC, but could still reach the target slump value of $150 \mathrm{~mm}$ and strength of $40 \mathrm{MPa}$. It was feasible to prepare RRAC using multiple recycling RCA for structural use in terms of strength;

- The RRAC under different replacement rates and different recycling numbers showed diversity in carbonation resistance. The increasing of both the replacement rate and recycling number resulted in the degradation of RRAC carbonation resistance. But RAC-3-25 and RAC-2-75 displayed a comparable carbonation resistance to the RAC-1100 one. For the multiple recycling RAC, it could achieve similar carbonation resistance as the previous generation's by reducing the substitution rate;

- The degradation of RRAC carbonation resistance was attributed to the continuous dropping in RRCA quality and weak ITZs caused by RRCA in concrete. But at a low replacement rate and low recycling number, such as RAC-1-25, the carbonation resistance of RAC was comparable or even superior to the NAC one. This resulted 
from the attached mortar on the surface of RCA which reacted with $\mathrm{CO}_{2}$ to refine the pore structures of RAC;

- The RRAC specimens after freeze-thaw cycles were more susceptible to be carbonated due to the freeze-thaw damages. The spalling of cement mortar and micro-cracks as a consequence of freeze-thaw cycles aggravated the degradation of carbonation resistance of RRAC, especially at a high replacement rate $(\geq 75 \%)$ and recycling number ( $\geq$ two generations). This was verified by results of SEM analysis;

- The carbonation depth of RRAC after freeze-thaw cycles was much lower than the protective thickness of reinforced concrete in the design code. All three generations of RRAC could be used in micro-frozen regions for engineering applications.

Author Contributions: Conceptualization, H.L. and P.Z.; methodology, P.Z.; validation, H.L., M.H., and P.Z.; formal analysis, C.C.; investigation, X.W.; resources, Z.Q.; data curation, Y.D.; writingoriginal draft preparation, M.H.; writing-review and editing, H.L. and M.H.; visualization, M.H.; supervision, P.Z.; project administration, P.Z.; funding acquisition, H.L. and P.Z. All authors have read and agreed to the published version of the manuscript.

Funding: This research was funded by the National Natural Science Foundation of China, grant number 52078068, State Key Laboratory of Silicate Materials for Architectures (Wuhan University of Technology), grant number SYSJJ2020-14, and Changzhou Science and Technology Project, grant number CJ20200079.

Institutional Review Board Statement: Not applicable.

Informed Consent Statement: Not applicable.

Data Availability Statement: Not applicable.

Acknowledgments: The authors thank Jiangsu Lvhe Environmental Technology Co. Ltd. for providing the recycled concrete aggregates.

Conflicts of Interest: The authors declare no conflict of interest.

\section{References}

1. Zhu, P.; Hua, M.; Liu, H.; Wang, X.; Chen, C. Interfacial evaluation of geopolymer mortar prepared with recycled geopolymer fine aggregates. Constr. Build. Mater. 2020, 259, 119849. [CrossRef]

2. Bidabadi, M.S.; Akbari, M.; Panahi, O. Optimum mix design of recycled concrete based on the fresh and hardened properties of concrete. J. Build. Eng. 2020, 32, 101483. [CrossRef]

3. Li, T.; Xiao, J.; Zhang, Y.; Chen, B. Fracture behavior of recycled aggregate concrete under three-point bending. Cem. Concr. Compos. 2019, 104, 103353. [CrossRef]

4. Kazmi, S.M.S.; Munir, M.J.; Wu, Y.-F.; Patnaikuni, I.; Zhou, Y.; Xing, F. Influence of different treatment methods on the mechanical behavior of recycled aggregate concrete: A comparative study. Cem. Concr. Compos. 2019, 104, 103398. [CrossRef]

5. Adessina, A.; Ben Fraj, A.; Barthélémy, J.-F.; Chateau, C.; Garnier, D. Experimental and micromechanical investigation on the mechanical and durability properties of recycled aggregates concrete. Cem. Concr. Res. 2019, 126, 105900. [CrossRef]

6. Zhu, P.; Hao, Y.; Liu, H.; Wang, X.; Gu, L. Durability evaluation of recycled aggregate concrete in a complex environment. J. Clean. Prod. 2020, 273, 122569. [CrossRef]

7. Martínez-García, R.; Jagadesh, P.; Fraile-Fernández, F.J.; Morán-del Pozo, J.M.; Juan-Valdés, A. Influence of Design Parameters on Fresh Properties of Self-Compacting Concrete with Recycled Aggregate-A Review. Materials 2020, 13, 5749. [CrossRef] [PubMed]

8. Kazmi, S.M.S.; Munir, M.J.; Wu, Y.-F.; Patnaikuni, I.; Zhou, Y.; Xing, F. Effect of recycled aggregate treatment techniques on the durability of concrete: A comparative evaluation. Constr. Build. Mater. 2020, 264, 120284. [CrossRef]

9. Xuan, D.; Zhan, B.; Poon, C.S. Assessment of mechanical properties of concrete incorporating carbonated recycled concrete aggregates. Cem. Concr. Compos. 2016, 65, 67-74. [CrossRef]

10. Maduabuchukwu Nwakaire, C.; Poh Yap, S.; Chuen Onn, C.; Wah Yuen, C.; Adebayo Ibrahim, H. Utilisation of recycled concrete aggregates for sustainable highway pavement applications; a review. Constr. Build. Mater. 2020, 235, 117444. [CrossRef]

11. Ying, J.; Han, Z.; Shen, L.; Li, W. Influence of Parent Concrete Properties on Compressive Strength and Chloride Diffusion Coefficient of Concrete with Strengthened Recycled Aggregates. Materials 2020, 13. [CrossRef]

12. Zhan, B.J.; Xuan, D.X.; Poon, C.S.; Scrivener, K.L. Characterization of interfacial transition zone in concrete prepared with carbonated modeled recycled concrete aggregates. Cem. Concr. Res. 2020, 136, 106175. [CrossRef]

13. Gholizadeh-Vayghan, A.; Bellinkx, A.; Snellings, R.; Vandoren, B.; Quaghebeur, M. The effects of carbonation conditions on the physical and microstructural properties of recycled concrete coarse aggregates. Constr. Build. Mater. 2020, 257, 119486. [CrossRef] 
14. Alhazmi, H.; Shah, S.A.; Mahmood, A. Sustainable Development of Innovative Green Construction Materials: A Study for Economical Eco-Friendly Recycled Aggregate Based Geopolymer Concrete. Materials 2020, 13, 4881. [CrossRef] [PubMed]

15. Tayeh, B.A.; Al Saffar, D.M.; Alyousef, R. The Utilization of Recycled Aggregate in High Performance Concrete: A Review. J. Mater. Res. Technol. 2020, 9, 8469-8481. [CrossRef]

16. Rangel, C.S.; Amario, M.; Pepe, M.; Martinelli, E.; Toledo Filho, R.D. Influence of Wetting and Drying Cycles on Physical and Mechanical Behavior of Recycled Aggregate Concrete. Materials 2020, 13, 5675. [CrossRef] [PubMed]

17. Li, L.G.; Zheng, J.Y.; Ng, P.-L.; Kwan, A.K.H. Synergistic cementing efficiencies of nano-silica and micro-silica in carbonation resistance and sorptivity of concrete. J. Build. Eng. 2021, 33, 101862. [CrossRef]

18. Courard, L.; Zhao, Z.; Michel, F. Influence of hydrophobic product nature and concentration on carbonation resistance of cultural heritage concrete buildings. Cem. Concr. Compos. 2021, 115, 103860. [CrossRef]

19. Zhou, Y.; Gencturk, B.; Willam, K.; Attar, A. Carbonation-Induced and Chloride-Induced Corrosion in Reinforced Concrete Structures. J. Mater. Civ. Eng. 2014, 27. [CrossRef]

20. Ekolu, S.O. A review on effects of curing, sheltering, and $\mathrm{CO} 2$ concentration upon natural carbonation of concrete. Constr. Build. Mater. 2016, 127, 306-320. [CrossRef]

21. Zhu, P.; Hao, Y.; Liu, H.; Wei, D.; Liu, S.; Gu, L. Durability evaluation of three generations of $100 \%$ repeatedly recycled coarse aggregate concrete. Constr. Build. Mater. 2019, 210, 442-450. [CrossRef]

22. Liu, F.; You, Z.; Yang, X.; Wang, H. Macro-micro degradation process of fly ash concrete under alternation of freeze-thaw cycles subjected to sulfate and carbonation. Constr. Build. Mater. 2018, 181, 369-380. [CrossRef]

23. Niu, D.; Xiao, Q.; Zhu, W. Concrete damage and neutralization under coupling effect of carbonation and freeze-thaw cycles. J. Wuhan Univ. Technol. Sci. Ed. 2012, 27, 353-357. [CrossRef]

24. He, Z.; Tang, S.W.; Zhao, G.S.; Chen, E. Comparison of three and one dimensional attacks of freeze-thaw and carbonation for concrete samples. Constr. Build. Mater. 2016, 127, 596-606. [CrossRef]

25. Chai, L.; Guo, L.; Chen, B.; Xu, Y. Interactive effects of freeze-thaw cycle and carbonation on tensile property of ecological high ductility cementitious composites for bridge deck link slab. Constr. Build. Mater. 2018, 186, 773-781. [CrossRef]

26. Fang, X.; Xuan, D.; Poon, C.S. Empirical modelling of CO2 uptake by recycled concrete aggregates under accelerated carbonation conditions. Mater. Struct. 2017, 50, 200. [CrossRef]

27. Guo, H.; Shi, C.; Guan, X.; Zhu, J.; Ding, Y.; Ling, T.-C.; Zhang, H.; Wang, Y. Durability of recycled aggregate concrete-A review. Cem. Concr. Compos. 2018, 89, 251-259. [CrossRef]

28. Yildirim, S.T.; Meyer, C.; Herfellner, S. Effects of internal curing on the strength, drying shrinkage and freeze-thaw resistance of concrete containing recycled concrete aggregates. Constr. Build. Mater. 2015, 91, 288-296. [CrossRef]

29. Deng, X.; Gao, X.; Wang, R.; Gao, M.; Yan, X.; Cao, W.; Liu, J. Investigation of microstructural damage in air-entrained recycled concrete under a freeze-thaw environment. Constr. Build. Mater. 2021, 268, 121219. [CrossRef]

30. Xiao, Q.H. Concrete Structure Durability in Freezing-Thawing Circumstance Based on Multi-Factor Effects. Ph.D. Thesis, Xían University of Architecture and Technology, Xi'an, China, 2010.

31. Mao, M.; Zhang, D.; Yang, Q.; Zhang, W. Study of Durability of Concrete with Fly Ash as Fine Aggregate under Alternative Interactions of Freeze-Thaw and Carbonation. Adv. Civ. Eng. 2019, 2019, 1-15. [CrossRef]

32. Safiuddin, M.; Alengaram, U.J.; Rahman, M.M.; Salam, M.A.; Jumaat, M.Z. Use Of Recycled Concrete Aggregate In Concrete: A Review. J. Civ. Eng. Manag. 2013, 19, 796-810. [CrossRef]

33. LI, Y.; WANG, R.; ZHAO, Y. Effect of coupled deterioration by freeze-thaw cycle and carbonation on concrete produced with coarse recycled concrete aggregates. J. Ceram. Soc. Japan 2017, 125, 36-45. [CrossRef]

34. Jin, L.; Jin, W.; Wang, H.; Xia, J. Multi-environmental time similarity theory and its application. J. Zhejiang Univ. 2010, 44, 789-797. [CrossRef]

35. Zhu, P.; Zhang, X.; Wu, J.; Wang, X. Performance degradation of the repeated recycled aggregate concrete with $70 \%$ replacement of three-generation recycled coarse aggregate. J. Wuhan Univ. Technol. Sci. Ed. 2016, 31, 989-995. [CrossRef]

36. ASTM C143 / C143M-20. Standard Test Method for Slump of Hydraulic-Cement Concrete; ASTM International: West Conshohocken, PA, USA, 2020.

37. ASTM C109 / C109M-20a. Standard Test Method for Compressive Strength of Hydraulic Cement Mortars (Using 2-in. or [50-mm] Cube Specimens); ASTM International: West Conshohocken, PA, USA, 2020.

38. GB/T 50082-2009. Standard for Test Methods of Long-Term Performance and Durability of Ordinary Concrete; China Architecture \& Building Press: Beijing, China, 2009.

39. Evangelista, L.; Guedes, M.; de Brito, J.; Ferro, A.C.; Pereira, M.F. Physical, chemical and mineralogical properties of fine recycled aggregates made from concrete waste. Constr. Build. Mater. 2015, 86, 178-188. [CrossRef]

40. Poon, C.S.; Shui, Z.H.; Lam, L. Effect of microstructure of ITZ on compressive strength of concrete prepared with recycled aggregates. Constr. Build. Mater. 2004, 18, 461-468. [CrossRef]

41. Etxeberria, M.; Vázquez, E.; Marí, A.; Barra, M. Influence of amount of recycled coarse aggregates and production process on properties of recycled aggregate concrete. Cem. Concr. Res. 2007, 37, 735-742. [CrossRef]

42. Kaliyavaradhan, S.K.; Ling, T.-C. Potential of CO2 sequestration through construction and demolition (C\&D) waste-An overview. J. CO2 Util. 2017, 20, 234-242. [CrossRef] 
43. Liang, C.; Lu, N.; Ma, H.; Ma, Z.; Duan, Z. Carbonation behavior of recycled concrete with CO2-curing recycled aggregate under various environments. J. CO2 Util. 2020, 39, 101185. [CrossRef]

44. Thomas, C.; Setién, J.; Polanco, J.A.; Alaejos, P.; Sánchez de Juan, M. Durability of recycled aggregate concrete. Constr. Build. Mater. 2013, 40, 1054-1065. [CrossRef]

45. Wang, Y.; Cao, Y.; Zhang, P.; Ma, Y.; Zhao, T.; Wang, H.; Zhang, Z. Water absorption and chloride diffusivity of concrete under the coupling effect of uniaxial compressive load and freeze-thaw cycles. Constr. Build. Mater. 2019, 209, 566-576. [CrossRef]

46. Zhang, P.; Wittmann, F.H.; Vogel, M.; Müller, H.S.; Zhao, T. Influence of freeze-thaw cycles on capillary absorption and chloride penetration into concrete. Cem. Concr. Res. 2017, 100, 60-67. [CrossRef]

47. Silva, R.V.; Neves, R.; de Brito, J.; Dhir, R.K. Carbonation behaviour of recycled aggregate concrete. Cem. Concr. Compos. 2015, 62, 22-32. [CrossRef]

48. Cai, H.; Liu, X. Freeze-thaw durability of concrete: Ice formation process in pores. Cem. Concr. Res. 1998, 28, 1281-1287. [CrossRef]

49. Wu, H.; Liu, Z.; Sun, B.; Yin, J. Experimental investigation on freeze-thaw durability of Portland cement pervious concrete (PCPC). Constr. Build. Mater. 2016, 117, 63-71. [CrossRef]

50. Wu, H.; Jin, W.; Yan, Y.; Xia, J. Environmental zonation and life prediction of concrete in frost environments. J. Zhejiang Univ. Eng. Sci. 2012, 46, 650-657.

51. GB/T 50476-2019. Standard for Design of Concrete Struction Durability; China Architecture \& Building Press: Beijing, China, 2019. 